\title{
The FAIRness of data management plans: an assessment of some European DMPs
}

\author{
FAIRness dos planos de gestão de dados: uma avaliação de alguns PGDs \\ Europeus
}

\section{FAIRness de los planes de gestión de datos: una evaluación de algunos PGDs Europeos}

\author{
Patricia Henning ${ }^{1 . a}$ \\ henningpatricia@gmail.com | https://orcid.org/0000-0003-0739-6442
}

Luis Olavo Bonino da Silva ${ }^{2, b}$

luiz.bonino@go-fair.org | https://orcid.org/o0oo-0002-1164-1351

Luís Ferreira Pires ${ }^{2, c}$

ferreirapires@utwente.nl | https://orcid.org/0000-0001-7432-7653

Marten van Sinderen ${ }^{2, b}$

marm.j.vansinderen@utwente.nl | https://orcid.org/o00o-0001-7118-1353

João Luís Rebelo Moreira ${ }^{2, b}$

j.luizrebelomoreira@utwente.nl | https://orcid.org/0000-0002-4547-7000

${ }^{1}$ Universidade Federal do Estado do Rio de Janeiro. Rio de Janeiro, RJ, Brasil.

2 University of Twente. Enschede, Netherlands.

a Doutorado em Ciências pela Fundação Oswaldo Cruz.

b Ph. D in Computer Science from the University of Twente.

${ }^{c}$ Ph. D in Electrical Engineering from the University of Twente.

\begin{abstract}
The FAIR principles have become a data management instrument for the academic and scientific community, since they provide a set of guiding principles to bring findability, accessibility, interoperability and reusability to data and metadata stewardship. Since their official publication in 2016 by Scientific Data - Nature, these principles have received worldwide recognition and have been quickly endorsed and adopted as a cornerstone of data stewardship and research policy. However, when put into practice, they occasionally result in organisational, legal and technological challenges that can lead to doubts and uncertainty as to whether the effort of implementing them is worthwhile. Soon after their publication, the European Commission and other funding agencies started to require that project proposals include a Data Management Plan (DMP) based on the FAIR principles. This paper reports on the adherence of DMPs to the FAIR principles, critically evaluating ten European DMP templates. We observed that the current FAIRness of most of these DMPs is only partly satisfactory, in that they address data best practices, findability, accessibility and sometimes preservation, but pay much less attention to metadata and interoperability.
\end{abstract}

Keywords: Data Management Plan; FAIR Principles; Research Data; Data Management. 


\section{RESUMO}

Os princípios FAIR tornaram-se um instrumento de gestão de dados para a comunidade acadêmica e científica, uma vez que fornecem um conjunto de princípios orientadores que facilitam a localização, acessibilidade, interoperabilidade e reutilização de dados e metadados. Desde sua publicação oficial em 2016 pela Scientific Data - Nature, esses princípios receberam reconhecimento mundial e foram rapidamente endossados e adotados como pilares da gestão de dados e das políticas de pesquisa. No entanto, quando postos em prática, apresentam ocasionalmente desafios organizacionais, jurídicos e tecnológicos que podem levar a dúvidas e incertezas quanto ao esforço em implementá-los. Logo após sua publicação, a Comissão Europeia e outras agências de financiamento começaram a exigir nas suas propostas de projetos um Plano de Gestão de Dados (PGD) com base nos princípios da FAIR. Este artigo relata a aderência dos PGDs aos princípios FAIR, avaliando criticamente dez modelos europeus de PGD. Observamos que o nível de FAIRness da maioria dos PGDs analisados ainda é parcialmente satisfatório, uma vez que abordam as melhores práticas de dados, localização, acessibilidade e, às vezes, preservação, mas dão pouca atenção aos metadados e a interoperabilidade.

Palavras-chave: Plano de Gestão de Dados; Princípios FAIR; Dados de Pesquisa; Gestão de Dados.

\section{RESUMEN}

Los principios FAIR se han convertido en una herramienta de gestión de datos para la comunidad académica y científica, ya que proporcionan un conjunto de principios rectores que facilitan la localización, accesibilidad, interoperabilidad y reutilización de la gestión de datos y metadatos. Desde su publicación oficial en 2016 por Scientific Data - Nature, estos principios han recibido reconocimiento mundial y fueron rápidamente respaldados y adoptados como pilares de la política de investigación y gestión de datos. Sin embargo, cuando se ponen en práctica, ocasionalmente presentan desafíos organizativos, legales y tecnológicos que pueden generar dudas e incertidumbres sobre el esfuerzo para implementarlos. Poco después de su publicación, la Comisión Europea y otras agencias de financiación comenzaron a exigir en sus propuestas de proyectos un Plan de Gestión de Datos (PGD) basado en los principios de FAIR. Este artículo informa sobre la adherencia de los PGD a los principios FAIR, evaluando críticamente diez modelos europeos de PGD. Observamos que el nivel de FAIRness de la mayoría de los PGD analizados sigue siendo parcialmente insatisfactorio, ya que abordan las mejores prácticas de datos, ubicación, accesibilidad y, a veces, preservación, pero prestan poca atención a los metadatos y la interoperabilidad.

Palabras clave: Plan de Gestión de Datos; Principios FAIR; Datos de investigación; Gestión de datos.

Contribuição dos autores:

Concepção e desenho do estudo: Patricia Henning, Luis Olavo Bonino da Silva, Luís Ferreira Pires, João Luís Rebelo Moreira, Marten van Sinderen.

Aquisição, análise ou interpretação dos dados: Patricia Henning, Luis Olavo Bonino da Silva, Luís Ferreira Pires, João Luís Rebelo Moreira.

Redação do manuscrito: Patricia Henning, Luis Olavo Bonino da Silva, Luís Ferreira Pires. Marten van Sinderen.

Revisão crítica do conteúdo intelectual: João Luís Rebelo Moreira, Luis Olavo Bonino da Silva, Luís Ferreira Pires, Marten van Sinderen.

Declaração de conflito de interesses: não há.

Fontes de financiamento: não houve.

Considerações éticas: não há.

Agradecimentos/Contribuições adicionais: não há.

Histórico do artigo: submetido: 27 dez. 2020 | aceito: 30 mar. 2021 | publicado: 31 ago. 2021.

Apresentação anterior: não há.

Licença CC BY-NC atribuição não comercial. Com essa licença é permitido acessar, baixar (download), copiar, imprimir, compartilhar, reutilizar e distribuir os artigos, desde que para uso não comercial e com a citação da fonte, conferindo os devidos créditos de autoria e menção à Reciis. Nesses casos, nenhuma permissão é necessária por parte dos autores ou dos editores. 
Reciis - Revista Eletrônica de Comunicação, Informação \& Inovação em Saúde, Rio de Janeiro, v. 15, n. 3, p. 722-735, jul.-set. 2021 [www.reciis.icict.fiocruz.br] e-ISSN 1981-6278

\section{INTRODUCTION}

The FAIR (Findable, Accessible, Interoperable and Reusable) principles for research data stewardship were established as a result of the 'Jointly designing the data FAIRPORT' international conference held in January 2014 at the Lorentz Centre in Leiden, the Netherlands. This conference brought together specialists from different countries and from different research areas to discuss the use, treatment and reuse of research data within the scope of open science. Broader dissemination of the FAIR principles started two years later, in March 2016, with the publication of the principles in Nature's Journal Scientific Data. Subsequently, the principles were quickly endorsed and adopted worldwide as a cornerstone of data stewardship and research policy. Consequently, adherence to these principles became a requirement, particularly for research agencies providing financial support, like the National Institutes of Health (NIH), the Australian National Data Services (ANDS), the National Science Foundation (NSF), and the European Commission (EC). The EC, for example, requires that each project proposal submission include a Data Management Plan (DMP) in accordance with the FAIR principles. Since then, the FAIR principles have been used as a guideline for best practices for data stewardship, consisting of a set of fifteen high-level, domain-independent data principles aimed at improving the findability, accessibility, interoperability and reusability of research data.

A DMP defines a strategy for managing data throughout the research lifecycle. It also brings more transparency and openness to projects, provides greater assurance that data will be accessible and (re)usable over time, and thus ensures return on investment. A consistent DMP is necessary for proper data stewardship, which can be achieved by following the FAIR principles. However, we observed that, in practice, the FAIR principles are subject to different interpretations, leading to different applications and implementations and, consequently, reduced effectiveness. Some studies acknowledge these problems and point out the difficulties in implementing FAIR in the context of Data Science. One of these studies reports on the FAIRness of thirty-eight data repositories used by Dutch researchers and students (DUNNING; AMAELE; BÖHMER, 2017). SURF (IMMING et al., 2018) also reported on six cases of FAIR data use in different domains. These two studies reached similar conclusions concerning the obstacles faced when implementing the FAIR principles. They conclude that possible reasons for these difficulties include the lack of supporting culture change, policies, regulations, licensing, protocols and metadata knowledge. These problems may arise from misunderstanding what the FAIR principles really are. The authors also identify that there is a tension between domain-specific needs and cross-domain interoperability. Boeckhou, Zielhuis, and Bredenoord (2018) make a critical appraisal of the FAIR principles considering ongoing discussions and developments on data sharing. They consider that the FAIR principles can help achieve more open science and provide a necessary step forward towards data stewardship. However, they claim that FAIR does not provide a complete set of guiding principles for improving data-driven science. They suggest that FAIR should be supplemented with other principles and conclude that the FAIR principles should be applied with responsibility, taking existing norms into consideration. Very recently, Europe's Research Library Network (LIBER) released the results of a survey conducted by its Research Data Management Working Group about the FAIRness of Repositories \& Their Data (IVANOVIĆ; SCHMIDT; GRIM; DUNNING, 2019). These results identified some good practices for the implementation of FAIRness at the repository level and analysed misunderstandings of the FAIR principles and misleading implementations.

These FAIR implementation difficulties led us to recognize the relevance of evaluating the FAIRness of some DMPs by identifying to what extent these plans adhere to the FAIR principles since the beginning of the research lifecycle. Therefore, this study sought to clarify the use (and misuse) of these principles in research DMPs. In our research, we assessed the FAIRness of ten European Data Management Plans. 
However, before starting this analysis, we tried to clarify what the FAIR principles are and what they are not. We also describe what a DMP is and how it relates to the FAIR principles. After assessing the DMPs through their templates, we concluded that, in some cases, the implementation is unsatisfactory or has not even happened in the manner it should have because the people who formulated them focused on good practices for findability and access but did not emphasize metadata and interoperability. We claim that DMPs can be improved by addressing these issues. Stronger adherence to the FAIR principles should have a positive impact on scientific data management and stewardship. We emphasise that we did not aim to evaluate or criticise the quality of European DMP templates, but rather assess the adherence of these ten different DMPs to the FAIR principles in terms of data and metadata.

\section{THE FAIR PRINCIPLES: A BRIEF LITERATURE REVIEW}

The FAIR acronym suggests that adherence to the principles makes it easier to find, access, reference, represent and combine data using qualified links, as well as identify the origin of data, manage authorisation via a specific license and, above all, ensure data reuse. Wilkinson et al. (2016) state that "distinct from peer initiatives that focus on the human scholar, the FAIR principles put specific emphasis on enhancing the ability of machines to automatically find and use the data, in addition to supporting its reuse by individuals" (WILKINSON et al., 2016). They also assert that the principles apply not only to data, but also to the algorithms, tools, and workflows that lead to these data. All components of the research process must be available to ensure transparency and reproducibility, and to maximise data reuse (WILKINSON et al., 2016).

\section{Findable:}

F1. (meta)data are assigned a globally unique and persistent identifier

F2. data are discribed with rich metadata (defined by R1 below)

F3. metadata clearly and explicitly include the identifier of the data it describes

F4. (meta)data are registered or indexed in a searchable resource

\section{Accessible:}

A1. (meta)data are retrievable by their identifier using a standardized communications protocol

A1.1. the protocol is free, open and universally implementable

A1.2. the protocol allows for an authentication and authorization pocedure, where necessary

A.2. metadata are accessible, even when the data are no longer available

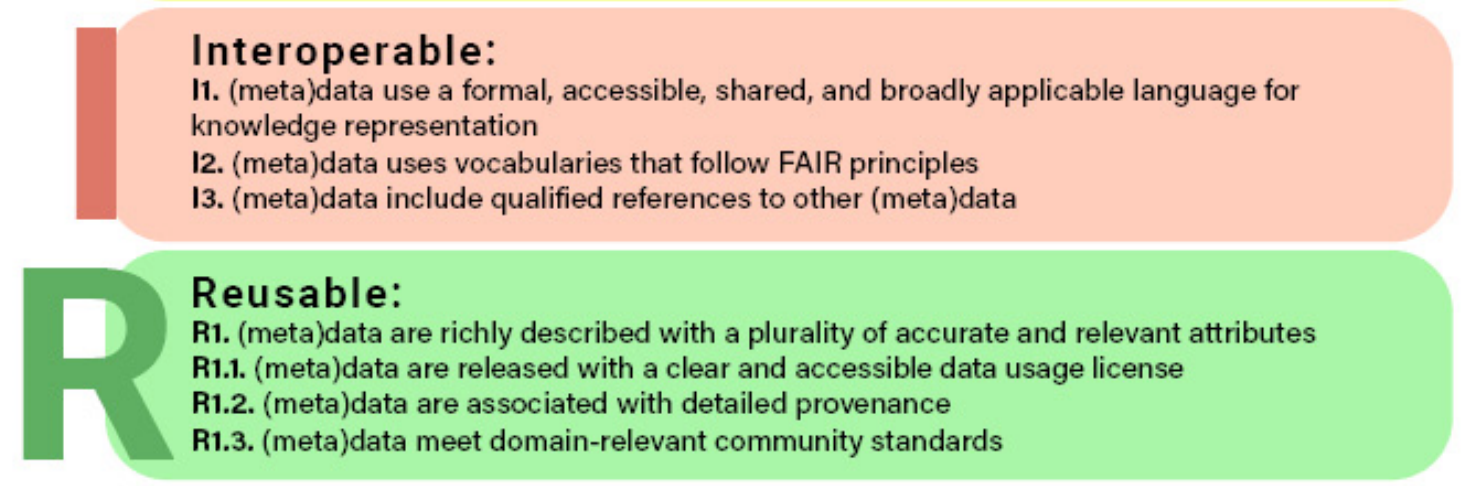

Figure 1 - The FAIR Principles

Source: prepared by the authors based on Wilkinson et al. (2016).

By definition, these principles do not detail how to achieve a state of FAIRness, but they simply describe a set of desired attributes, qualities and behaviours that move a digital resource towards FAIRness. Therefore, without clear procedures, differing interpretations sometimes lead to proper implementations. Boeckhou, Zielhuis, and Bredenoord (2018) raised important questions that should be considered. They 
argue that these principles, while creating elements that promote data sharing and reuse and still improve data management, do not reach the necessary level of detail regarding the normative problems associated with data design choices, participant's rights and ways to evaluate data sharing.

We also deem it relevant to point out what FAIR is not. Mons et al. (2017) state that the FAIR Principles are not a standard and, therefore, they are not comparable to Linked Data or the Semantic Web, although these approaches can be used to achieve a higher level of FAIRness. FAIR does state that computers must be capable of accessing a data publication autonomously, unaided by their human operators. Being FAIR is not the same as being Open. FAIR is not exclusive to Life Sciences, either: the principles may be equally applied to any data or any service, in any discipline (MONS et al., 2017).

FAIR is in an early stage and it still requires much discussion, even in countries where Data Science is already well underway. We agree with Boeckhou, Zielhuis \& Bredenoord (2018) in that facilitating data sharing and reuse may be a prerequisite for reaping the benefits of new forms of data-driven research, and that is the intended role to be played by FAIR.

\section{FAIR PRINCIPLES IN DATA MANAGEMENT PLANS}

The amount of digital data generated in the scientific world is increasing rapidly, so researchers are already facing a 'research data deluge'. Therefore, researchers have realised that they must organise their research data, not only to comply with the demands of funding agencies, but also to increase the reuse and exposure of their own data. This can be accomplished through a DMP, which is a formal document that details how research data will be managed during the data life cycle. However, many people still wonder how DMPs and the FAIR principles are related and how they should work together. Figure 2 shows the components of a FAIR ecosystem according to the European Commission Expert Group on FAIR Data (EUROPEAN COMISSION, 2018).

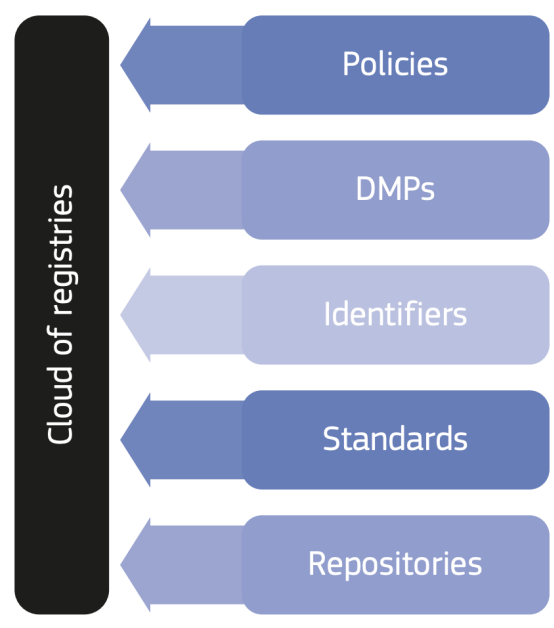

Figure 2 - The components of a FAIR ecosystem

Source: European Commission (2018).

While 'Policies' establish rules and regulations, 'DMPs' assist in planning strategies, administration, interoperability and data sharing, 'Identifiers' are necessary to locate data and metadata, 'Standards' are necessary to achieve data interoperability, and 'Repositories' are required for the storage of data and metadata.

A DMP should be produced at the beginning of the research lifecycle, as it provides an opportunity to reflect on the decisions that will affect all data activities and properties, including their FAIRness. They may 
seem to be an administrative responsibility at first, but the process of creating and maintaining DMPs can provide important insights and lessons related to gathering, curating and disseminating data, building a common understanding across a project from an early stage and reducing administrative burden. The Dutch Centre for Life Science claims that the FAIR principles provide excellent guidelines for data management planning. Their benefits are listed in Box 1.

\section{Box 1 - FAIR benefits for data management planning}

\begin{tabular}{|l|l|}
\hline To ensure Findability & $\begin{array}{l}\text { Select a data repository at an early stage and check out its data format and } \\
\text { metadata requirements; Make sure the data can get a persistent identifier } \\
\text { so that it can be cited; Maybe select a catalogue to make your data more } \\
\text { findable, especially if the repository is more generic in nature. }\end{array}$ \\
\hline To ensure Accessibility & $\begin{array}{l}\text { Guarantee longevity of the data (e.g., by submitting it to a repository that has } \\
\text { certification like the Data Seal of Approval or an ISO certification); Check and } \\
\text { describe the legal conditions under which the data can be made available (this } \\
\text { is generally easier to do before you have collected and interpreted the data); } \\
\text { Establish an embargo period if necessary; Make sure your Information and } \\
\text { Communications Technology infrastructure will keep the data available even in } \\
\text { the event of equipment failure or human error. }\end{array}$ \\
\hline To ensure Interoperability & $\begin{array}{l}\text { Select commonly used data formats; Select commonly used vocabularies for } \\
\text { data items. }\end{array}$ \\
\hline To ensure Reusability & $\begin{array}{l}\text { Make sure you keep proper provenance information (i.e., details about how } \\
\text { and where the data was generated, including machine settings, and details } \\
\text { about all processing steps, such as the software tools with their versions } \\
\text { and parameters); Select the right minimal metadata standard and collect } \\
\text { the necessary metadata (many minimal metadata standards are included in } \\
\text { the FAIRsharing.org repository); Select a license for the data (preferably an } \\
\text { open license) and the associated software tools. Make sure the important } \\
\text { conclusions of your study will not only be available in a paper in narrated form } \\
\text { but also in a digital file (e.g.: a nanopublication). }\end{array}$ \\
\hline
\end{tabular}

Source: prepared by the authors, based on Dutch Centre for Life Science (2019).

\section{RESEARCH METHODOLOGY}

This evaluation was carried out in an exploratory study in which we analysed the FAIRness prescribed by ten different DMP templates from research funding agencies and research organisations in Europe. We selected these specific organisations because we consider them to be representative of current European research and we had access to their documentation. Box 2 gives the sources of information used in this research.

\section{Box 2 - DMP templates, institution names, and locations}

(continua)

\begin{tabular}{|c|c|c|c|c|}
\hline & Acronym & Institutions & Document & Document URL \\
\hline 1 & $\mathrm{EC}$ & $\begin{array}{l}\text { European } \\
\text { Commission }\end{array}$ & $\begin{array}{l}\text { Directorate-General for } \\
\text { Research \& Innovation } \\
\text { H2020. Programme } \\
\text { Guidelines on FAIR Data } \\
\text { Management in Horizon }\end{array}$ & $\begin{array}{l}\text { http://ec.europa.eu/research/participants/data/ } \\
\text { ref/h2020/grants manual/hi/oa pilot/h2020-hi- } \\
\text { oa-data-mgt en.pdf } \\
\text { Version analysed: } 26 \text { July } 2016\end{array}$ \\
\hline 2 & SE & Science Europe & $\begin{array}{l}\text { Practical Guide to the } \\
\text { International Alignment } \\
\text { of Research Data } \\
\text { Management. }\end{array}$ & $\begin{array}{l}\text { https://www.scienceeurope.org/wp-content/ } \\
\text { uploads/2018/12/SE RDM Practical Guide } \\
\text { Final.pdf } \\
\text { Version analysed: } 29 \text { January } 2019\end{array}$ \\
\hline
\end{tabular}


(conclusão)

\begin{tabular}{|c|c|c|c|c|}
\hline & Acronym & Institutions & Document & Document URL \\
\hline 3 & ERC & $\begin{array}{l}\text { European } \\
\text { Research } \\
\text { Council }\end{array}$ & $\begin{array}{l}\text { Data Management Plan } \\
\text { Template }\end{array}$ & $\begin{array}{l}\text { https://erc.europa.eu/content/erc-data- } \\
\text { management-plan-template and https://erc. } \\
\text { europa.eu/sites/default/files/document/file/ } \\
\text { ERC info document-Open Research Data and } \\
\text { Data Management Plans.pdf } \\
\text { Version analysed: } 12 \text { April, } 2017\end{array}$ \\
\hline 4 & CESSDA & $\begin{array}{l}\text { Consortium of } \\
\text { European Social } \\
\text { Science Data } \\
\text { Archives }\end{array}$ & $\begin{array}{l}\text { Adapt your Data } \\
\text { Management Plan. A list } \\
\text { of Data Management } \\
\text { Questions based on } \\
\text { Expert Tour Guide on } \\
\text { Data Management }\end{array}$ & $\begin{array}{l}\text { https://www.cessda.eu/content/download/3844/ } \\
\text { 35033/file/20171117DMPQuestionsCESSDA } \\
\text { ExpertTourGuide.pdf } \\
\text { Version analysed: } 2017\end{array}$ \\
\hline 5 & NWO & $\begin{array}{l}\text { The Netherlands } \\
\text { Organisation } \\
\text { for Scientific } \\
\text { Research }\end{array}$ & $\begin{array}{l}\text { Data Management Plan } \\
\text { Template }\end{array}$ & $\begin{array}{l}\text { https://www.nwo.nl/en/policies/open+science/ } \\
\text { data+management } \\
\text { Version analysed: prior to } 2020\end{array}$ \\
\hline 6 & ZonMV & $\begin{array}{l}\text { The Netherlands } \\
\text { Organisation } \\
\text { for Health } \\
\text { Research and } \\
\text { Development }\end{array}$ & $\begin{array}{l}\text { Instructions for } \\
\text { composing a ZonMw } \\
\text { data management plan }\end{array}$ & $\begin{array}{l}\text { https://www.zonmw.nl/fileadmin/zonmw/ } \\
\text { Instruction ZonMw DMP Eng- okt } 201702 \\
\frac{\text { def.pdf }}{\text { Version analysed: October } 2017}\end{array}$ \\
\hline 7 & DANS & $\begin{array}{l}\text { Data Archiving } \\
\text { and Networked } \\
\text { Services }\end{array}$ & $\begin{array}{l}\text { Data Management Plan } \\
\text { for Scientific }\end{array}$ & $\begin{array}{l}\text { https://dans.knaw.nl/en/about/organisation- } \\
\text { and-policy/information-material/ } \\
\text { DANSdatamanagementplanjanuari2015UK.pdf } \\
\text { Version analysed: January } 2015\end{array}$ \\
\hline 8 & WT & Wellcome Trust & $\begin{array}{l}\text { Wellcome Trust } \\
\text { Template }\end{array}$ & $\begin{array}{l}\text { https://dmponline.dcc.ac.uk/template } \\
\text { export/1672128455.pdf } \\
\text { Version analysed: } 18 \text { October } 2018\end{array}$ \\
\hline 9 & DCC & $\begin{array}{l}\text { Digital Curation } \\
\text { Centre }\end{array}$ & $\begin{array}{l}\text { DIGITAL CURATION } \\
\text { CENTRE Template }\end{array}$ & $\begin{array}{l}\text { https://dmponline.dcc.ac.uk/template } \\
\text { export/1638514350.pdf } \\
\text { Version analysed: } 18 \text { May } 2018\end{array}$ \\
\hline 10 & UT & $\begin{array}{l}\text { University of } \\
\text { Twente }\end{array}$ & Data Management Plan & $\begin{array}{l}\text { https://www.utwente.nl/en/products-services/!/ } \\
\text { product/p885008/research-data-management } \\
\text { Version analysed: } 2019\end{array}$ \\
\hline
\end{tabular}

Source: prepared by the authors.

We noted that some DMP templates consist of a list of questions, while others provide a textual template with empty spaces and guidelines for filling them in. Even though the DMPs have different formats and scopes, they have the same goal of helping researchers plan the management of their research data.

We analysed each template and any associated guidelines for adherence to the fifteen FAIR principles, considering data and metadata separately. We classified each DMP with respect to each FAIR principle according to the three compliance levels shown in Box 3 . 


\section{Box 3 - Compliance levels for each FAIR principle}

\begin{tabular}{|l|l|}
\hline Fully Compliant (+) & $\begin{array}{l}\text { The template and any associated guidelines are fully compliant with the FAIR } \\
\text { principles. }\end{array}$ \\
\hline Partially Compliant (+/-) & $\begin{array}{l}\text { The template and any associated guidelines are partially compliant with the FAIR } \\
\text { principles; this occurs when FAIR principles are inaccurately or ambiguously } \\
\text { requested or incomplete in the templates. }\end{array}$ \\
\hline Not Compliant (-) & $\begin{array}{l}\text { The FAIR principles are not explicitly mentioned in the template or in its associated } \\
\text { guidelines, nor the concerns and expected behaviours }\end{array}$ \\
\hline
\end{tabular}

Source: prepared by the authors.

\section{ASSESSMENTS OF DMP TEMPLATES}

Because the FAIR principles were originally conceived to guide good practices for managing either data (or other digital resources) and their metadata, we assessed the DMP templates mentioned in Box 2 separately with respect to data and metadata. Assessment of the 'A1' principle relies on assessment of 'A1.1' and 'A1.2', and similarly for 'R1' with regard to 'R1.1', 'R1.2', and 'R1.3'.

Tables 1 and 2 show the data and metadata results, respectively, from the compliance level analysis for each DMP template with respect to each FAIR principle. The columns in Tables 1 and 2 indicate the DMP templates identified by their acronyms. The rows of Tables 1 and 2 correspond to the FAIR principles.

\section{Table 1-DMP template compliance with respect to data}

\begin{tabular}{|c|c|c|c|c|c|c|c|c|c|c|}
\hline $\begin{array}{c}\text { FAIR } \\
\text { Principles }\end{array}$ & EC & SE & ERC & CESSDA & NWO & ZonMV & DANS & WT & DCC & UT \\
\hline F1 & + & + & + & + & + & + & + & + & + & + \\
\hline $\mathbf{F 2}$ & $+/-$ & + & + & $+/-$ & $+/-$ & + & + & + & $+/-$ & $+/-$ \\
\hline F3 & - & + & - & - & - & - & - & - & - & - \\
\hline F4 & + & + & + & + & + & + & + & + & + & + \\
\hline A1 & + & + & + & + & + & + & + & + & + & + \\
\hline A1.1 & + & + & + & + & + & + & + & + & + & + \\
\hline A1.2 & + & + & + & + & + & + & + & + & + & + \\
\hline I1 & - & $+/-$ & - & - & - & + & - & - & - & - \\
\hline 12 & $+/-$ & $+1-$ & + & $+/-$ & - & $+/-$ & $-+/-$ & $+/-$ & $+/-$ & $+/-$ \\
\hline I3 & $+1-$ & + & + & - & + & + & + & + & - & - \\
\hline R1 & + & + & + & $+/-$ & $+/-$ & $+/-$ & $+/-$ & $+/-$ & $+/-$ & $+/-$ \\
\hline R1.1 & + & + & + & + & + & + & + & + & + & + \\
\hline R1.2 & + & + & + & + & $+/-$ & $+/-$ & $+/-$ & $+/-$ & $+/-$ & $+/-$ \\
\hline R1.3 & + & + & + & - & + & + & + & + & + & + \\
\hline
\end{tabular}

Source: prepared by the authors.

Note: A2 was omitted in Table 1 because we determined that it does not concern data, only metadata. 


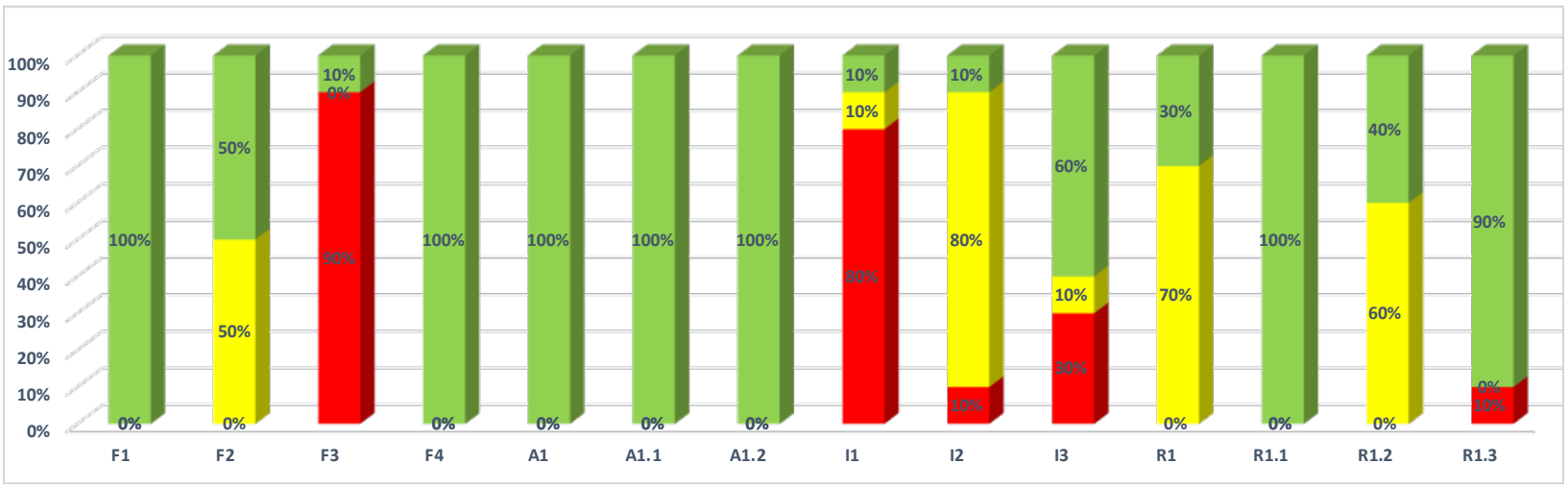

Figure 3 - Aggregate compliance of the DMP templates for each FAIR principle with respect to data Source: prepared by the authors.

'Findable'. 'F1': This is properly covered by all DMP templates with regard to data. 'F2': Half of the templates mention that data need to be described using rich metadata, while the other half does not mention this requirement. 'F3': The FAIR principles require that a persistent identifier be included in the metadata description, yet $90 \%$ of the templates do not prescribe this explicitly. 'F4': This is well covered concerning data by all DMP templates since they all prescribe depositing the data in a trustworthy repository.

'Accessible'. 'A1', 'A1.1', and 'A1.2': Every DMP template requires a globally unique and persistent identifier and also requires that the data be registered or indexed in a searchable resource (i.e., trustworthy repository), addressing principles 'A1', 'A1.1' and 'A1.2'. Every trustworthy repository offers a persistent identifier and uses a standardized communication protocol (open and free), allowing authentication and authorization procedures. 'A2'. This principle is specific to metadata and therefore was only considered in the metadata assessment.

'Interoperable'. 'I1': $80 \%$ of the DMP templates do not even mention the requirement that a formal, accessible, shared and broadly applicable language should be used for data knowledge representation. This means that this principle is not sufficiently covered by DMP templates, which require improvement. 'I2': $80 \%$ of the DMP templates request the use of vocabularies to describe the data without specifying that they must follow the FAIR principles (i.e., the vocabularies must have persistent identifiers, be described with rich metadata, be indexed in a search engine, have a proper license, etc.). 'I3': 60\% of the DMP templates mention the importance of data being linked to other data, but the other $40 \%$ ignore this requirement.

'Reusable'. 'R1': 70\% of DMP templates emphasise that data must be richly described with a plurality of accurate and relevant attributes. 'R1.1': All DMP templates require a clear and accessible data usage license. 'R1.2': 40\% clearly state that data must be associated with detailed provenance. 'R1.3': 90\% mention that data must comply with domain-relevant community standards. This means that $\mathrm{R}$ principles are widely covered by the DMP templates. 


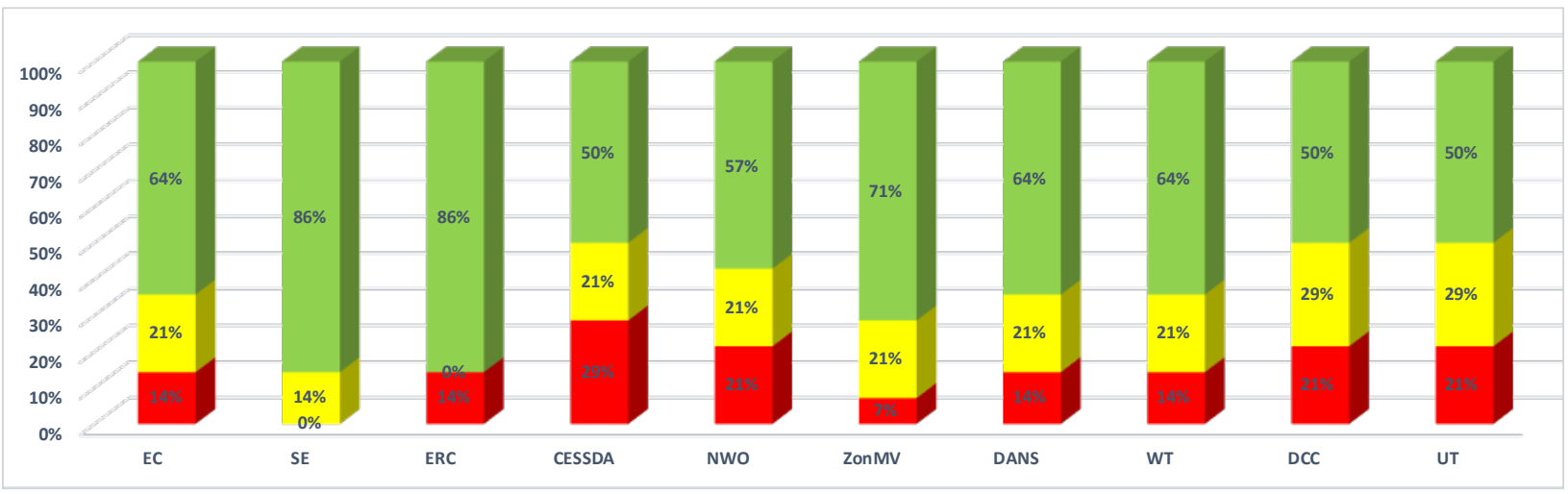

Figure 4 - Compliance of each DMP template with each FAIR principle with respect to data Source: prepared by the authors.

As shown in Figure 4, all DMP templates comply with at least 50\% of the FAIR principles concerning data. The DMP templates with the highest compliance with these principles are SE and ERC, which were both evaluated as fully compliant with $86 \%$ of the principles. If we consider compliance levels, SE is almost $100 \%$ FAIR with respect to data.

Table 2 - DMP template compliance with respect to metadata

\begin{tabular}{|c|c|c|c|c|c|c|c|c|c|c|}
\hline $\begin{array}{c}\text { FAIR } \\
\text { Principles }\end{array}$ & EC & SE & ERC & CESSDA & NWO & ZonMV & DANS & WT & DCC & UT \\
\hline F1 & - & + & - & - & - & - & - & - & - & - \\
\hline F3 & - & + & $+/-$ & - & - & - & - & - & - & - \\
\hline F4 & $+/-$ & + & + & - & - & + & - & - & - & - \\
\hline A1 & $+/-$ & + & $+/-$ & - & - & $+/-$ & - & - & - & - \\
\hline A1.1 & $+/-$ & + & $+1-$ & - & - & $+/-$ & - & - & - & - \\
\hline A1.2 & $+/-$ & + & $+/-$ & - & - & $+/-$ & - & - & - & - \\
\hline A2 & $+/-$ & + & $+/-$ & - & - & - & $+/-$ & $+/-$ & - & - \\
\hline I1 & - & $+/-$ & + & - & - & + & - & - & - & - \\
\hline 12 & $+/-$ & $+/-$ & $+/-$ & - & - & - & - & - & - & - \\
\hline $\mathbf{1 3}$ & - & - & - & - & - & - & - & - & - & - \\
\hline R1 & $+/-$ & $+/-$ & $+/-$ & - & $+/-$ & $+/-$ & $+/-$ & $+/-$ & - & $+/-$ \\
\hline R1.1 & - & - & - & - & - & - & - & - & - & - \\
\hline R1.2 & - & - & - & - & - & - & - & - & - & - \\
\hline R1.3 & + & + & + & - & + & + & + & + & + & + \\
\hline
\end{tabular}

Source: prepared by the authors.

Note: F2 was omitted in Table 2 because we concluded that FAIR principles state that only data are described with rich metadata. 


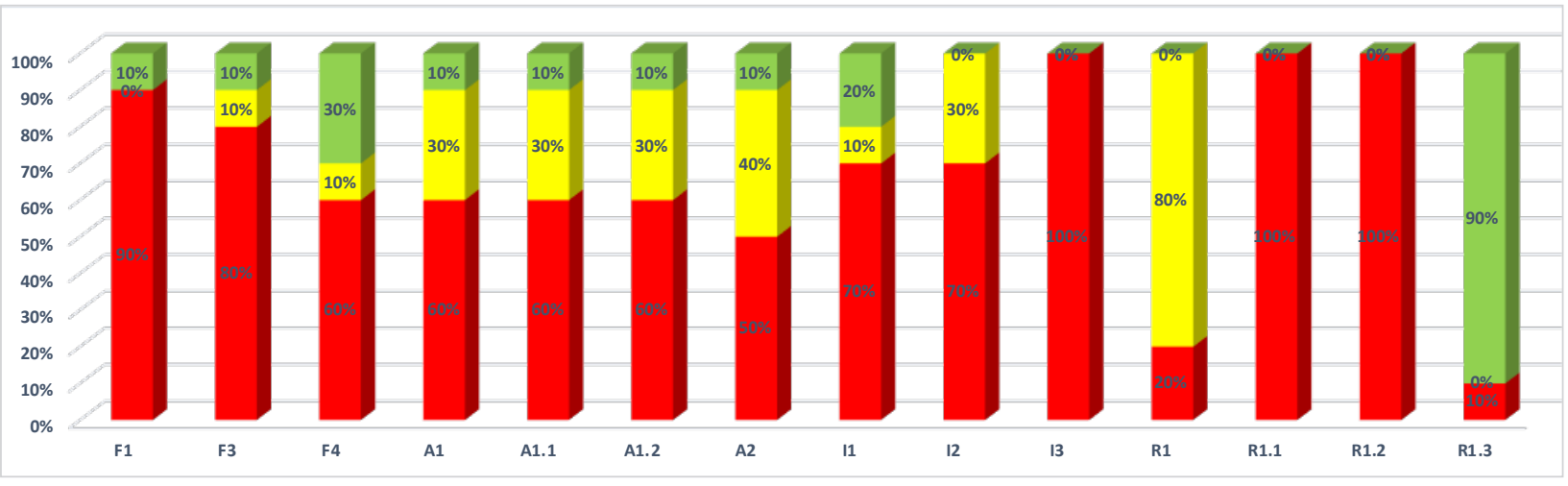

Figure 5 - Aggregate compliance of the DMP templates for each FAIR principle with respect to metadata Source: prepared by the authors.

'Findable'. 'F1': Only 10\% of the DMP templates require a persistent identifier for metadata. This principle requires that metadata descriptions mention the inclusion of a persistent identifier; however, $80 \%$ of the DMP templates do not mention one; 'F4': Only 30\% mention that metadata must be registered or indexed in a searchable resource (i.e., trustworthy repository).

'Accessible'. 'A1': We noticed that only 10\% state that metadata must be retrievable using an identifier through a standard communication protocol. 'A1.1' and 'A1.2': 40\% of the DMP templates mention that the protocol must be open, free and universally implementable, or that the protocol must support authentication and authorisation where necessary when referring to metadata.

'Interoperable'. 'I1': $30 \%$ of the DMP templates mention a formal, accessible, shared and broadly applicable language for metadata knowledge representation. This means that this principle is not prescribed by most of DMP templates, which require improvement. 'I2': 30\% of the DMP templates mention, but not explicitly, that metadata should be described by vocabularies that follow the FAIR principles. 'I3': None of the DMP templates prescribe that metadata should be linked to other (meta)data.

'Reusable'. 'R1': Only 80\% of the DMP templates emphasise that metadata must be richly described with a plurality of accurate and relevant attributes considering that most of them mention that metadata should comply with domain-relevant community standards. 'R1.1': None of the DMP templates require clear and accessible metadata usage licenses. 'R1.2': None of the DMP templates require that the metadata be associated with detailed provenance, but 'R1.3': $90 \%$ of the DMP templates require that metadata comply with domain-relevant community standards.

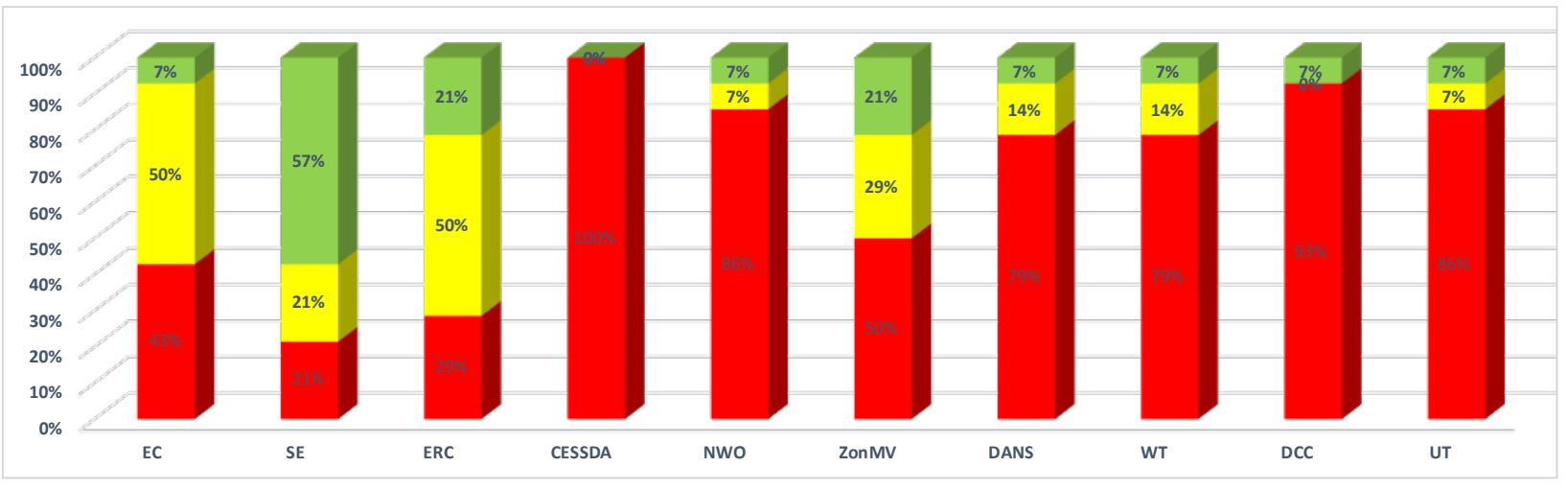

Figure 6 - Compliance of each DMP template with each FAIR principle with respect to metadata Source: prepared by the authors. 
In our analysis, we concluded that greater focus should be placed on metadata in DMP templates. Figure 6 shows that some DMP templates, like CESSDA, do not mention metadata at all, while NWO, DANS, WT, DCC, and UT show a relatively low level of metadata FAIRness. SE has the highest degree of FAIRness, being $57 \%$ fully compliant with respect to metadata and $21 \%$ partially compliant.

\section{DISCUSSION}

This assessment provides a critical view of the adoption of FAIR principles by some DMP templates in Europe. Three major structural problems were identified:

a) DMP templates are more concerned with data adhering to the FAIR principles than metadata. This makes it difficult for the templates analysed to achieve a higher level of FAIR compliance. This may be because the DMP template developers believed that metadata is not the researcher's responsibility. This is a misunderstanding since, in order to comply with FAIR principles, the DMP has to pay the same attention to metadata as to data. Principle ' $\mathrm{F} 3$ ' prescribes that metadata should clearly and explicitly include the identifier of the data they describe. Unfortunately, this is only mentioned in the Science Europe DMP template. We also know that metadata should be aligned by domain, and for this reason researchers must pay attention to those specifications. Some initiatives are being started to help researchers identify or create metadata in their domains and incorporate them into a specific DMP template. An example of this type of initiative is that of GO FAIR and Research Data Alliance (RDA), which began a series of workshops to encourage the creation of Machine Metadata (M4M) enabling any self-identified stakeholder to define and promote the reuse of standardized, comprehensive machine-actionable metadata (WITTENBURG et al., 2019).

b) Interoperability is challenging. Principle 'I1' had the lowest degree of adherence across all DMP templates since only SE explicitly mentioned this principle. We agree with Bishop and Hank (2018), who stated that interoperability principles can represent the greatest challenge as they require a more sophisticated understanding of discipline-specific languages and standards. Furthermore, some data users may not be familiar with the encoding of the data they use and misunderstand the knowledge representation language. They say that both standards and languages are at an early stage of development in some fields and areas of knowledge. Principle 'I2' was poorly incorporated into DMP models, since most DMP templates only partially adhere to it. We know that metadata, vocabulary, and ontologies are created for specific domains, and only a few of them follow FAIR principles. Finally, compared to other principles, the principles of interoperability are less well known and more expensive to implement. Furthermore, fewer skilled professionals are available to assist with interoperability (BISHOP; HANK, 2018).

c) With regard to reusability principles, the DMP templates are slightly satisfactory. Even though all of them require licenses to use, and almost all are concerned about domain-specific data standards, the major problem regarding reusability is principle 'R1.2', which has also been confirmed in a study by Europe's Research Library Network (IVANOVIĆ; SCHMIDT; GRIM; DUNNING, 2019), which states that the terms 'rich metadata models' and 'metadata provenance' are misinterpreted. We deem metadata FAIRness to be unsatisfactory because almost all of the DMP templates analysed show poor adherence to the FAIR principles regarding metadata. We understand that metadata patterns are not always structured according to the FAIR principles, which makes adherence to the principles difficult. Only SE managed to reach a reasonable level of metadata FAIRness. 
Reciis - Revista Eletrônica de Comunicação, Informação \& Inovação em Saúde, Rio de Janeiro, v. 15, n. 3, p. 722-735, jul.-set. 2021 [www.reciis.icict.fiocruz.br] e-ISSN 1981-6278

\section{FINAL REMARKS}

This assessment gives us several insights into the actual requirements of DMP templates regarding their levels of data and metadata FAIRness. Our goal was not to evaluate the quality of DMP templates, but to investigate their degree of compliance with the FAIR principles. Some of them may have been created before the FAIR principles were formally published, so the people who developed these templates were simply unaware of these principles.

We claim that a DMP is essential in order to ensure proper data management, archiving, preservation and reuse. For this reason, DMP templates should be as FAIR as possible. We also believe that the scientific community is undergoing an evolving structural change with the adoption of FAIR in its research practices, which should be seen as a challenge to be faced. Our research indicates that DMP templates should pay more attention to metadata if they truly wish to achieve a higher degree of FAIRness. We have confirmed previous research, namely that more energy should be invested in the principles related to interoperability, which are considered the most complex to implement.

We conclude that the main obstacle to implementing the FAIR principles is not their subjective interpretation or even their acceptance by the scientific community, but rather the initial cost of total operationalisation, which can be completely recovered later through the benefits of achieving higher levels of FAIRness. This will never happen if everyone interprets and implements the principles in a different way. We believe that identifying and solving these problems will increase the FAIRness of DMP templates, as well as create a better understanding of the essence of the FAIR principles, which we deem vital to the advancement of Data Science.

\section{REFERENCES}

BISHOP, Bradley Wade; HANK, Carolyn. Measuring FAIR Principles to Inform Fitness for Use. International Journal of Digital Curation, Edinburgh, v. 13, n. 1, p. 35-46, 2018. Available from: http://www.ijdc.net/article/ view/630/514. Cited in: 2020 Mar. 23.

BOECKHOU, Martin; ZIELHUIS, Gerhard A.; BREDENOORD, Annelien L. 2018. The FAIR guiding principles for data stewardship: fair enough?. European Journal of Human Genetics, Basingstoke, v. 26, p. 931-936, 2018. DOI: https://doi.org/10.1038/s41431-018-0160-0. Available from: https://www.nature.com/articles/s41431018-0160-0. Cited in: 2020 Mar. 23.

DUNNING, Alastair; AMAELE, Madeleine de; BÖHMER, Jasmin. Are the FAIR Data Principles fair?. In: INTERNATIONAL DIGITAL CURATION CONFERENCE, 12., 2017, Edinburgh. Zenodo, [s. I.], 2017. Preprint. DOI: http://doi.org/10.5281/zenodo.321423. Available from: https://zenodo.org/record/321423\#.W4QjbegzZaR. Cited in: 2020 Mar. 23.

DUTCH CENTRE FOR LIFE SCIENCE (DTL). Data Management Planning. [S. I.]: Dutch Techcentre for Life Sciences, 2019. Available from: https://www.dtls.nl/fair-data/research-data-management/data-managementplanningl. Cited in: 2020 Mar. 23.

EUROPEAN COMMISSION. Directorate General for Research and Innovation. Turning FAIR data into reality: final report and action plan. Brussels: European Union, 2018. E-book. DOI: https://www.doi.org/10.2777/1524. Available from: https://ec.europa.eu/info/sites/info/files/turning_fair_into_reality_1.pdf. Cited in: 2020 Mar. 23.

IMMING, Melanie et al. FAIR data advanced use cases: from principles to practice in the Netherlands. Zenodo, [s. I.], 2018. DOI: http://doi.org/10.5281/zenodo.1250535. Available from: https://zenodo.org/record/1250535\#. Wyl3RkiFNaQ. Cited in: 2020 Mar. 23.

IVANOVIĆ, Dragan; SCHMIDT, Birgit; GRIM, Rob; DUNNING, Alastair. FAIRness of repositories \& their data: a report from LIBER's research data management working group. Zenodo, [s. I.], 2019. Available from: https:// zenodo.org/record/3251593\#.XXJmBigzZ1t. Cited in: 2020 Mar. 23. 
MONS, Barend et al. Cloudy, increasingly FAIR; revisiting the FAIR Data guiding principles for the European Open Science Cloud. Information Services \& Use, [s. I.], v. 37, n. 1, p. 1-8, 2017. DOI: http://dx.doi. org/10.3233/ISU-170824. Available from: https://www.researchgate.net/publication/313833725_Cloudy increasingly FAIR Revisiting the FAIR Data guiding principles for the European Open Science Cloud. Cited in: 2020 Mar. 23.

WILKINSON, Mark D. et al. The FAIR Guiding Principles for scientific data management and stewardship. Scientific Data, [s. I.], v. 3, p. 160018, 2016. DOI: https://doi.org/10.1038/sdata.2016.18. Available from: https://www.nature.com/articles/sdata201618. Cited in: 2020 Mar. 23.

WITTENBURG, Peter et al. The FAIR Funder: a pilot programme to make it easy for funders to require and for grantees to produce FAIR Data. 2019. ArXiv, [s. I.], 2019. Available from: https://arxiv.org/ftp/arxiv/ papers/1902/1902.11162.pdf. Cited in: 2020 Mar. 23. 